PREPARED FOR THE U.S. DEPARTMENT OF ENERGY, UNDER CONTRACT DE-AC02-76-CHO-3073

PPPL-3119

PPPL-3119

1. UC-426

\title{
ALFVÉNIC BEHAVIOR OF ALPHA PARTICLE DRIVEN ION CYCLOTRON EMISSION IN TFTR
}

BY

S. CAUFFMAN, R. MAJESKI, K.G. MCCLEMENTS AND R.O. DENDY

JULY 1995
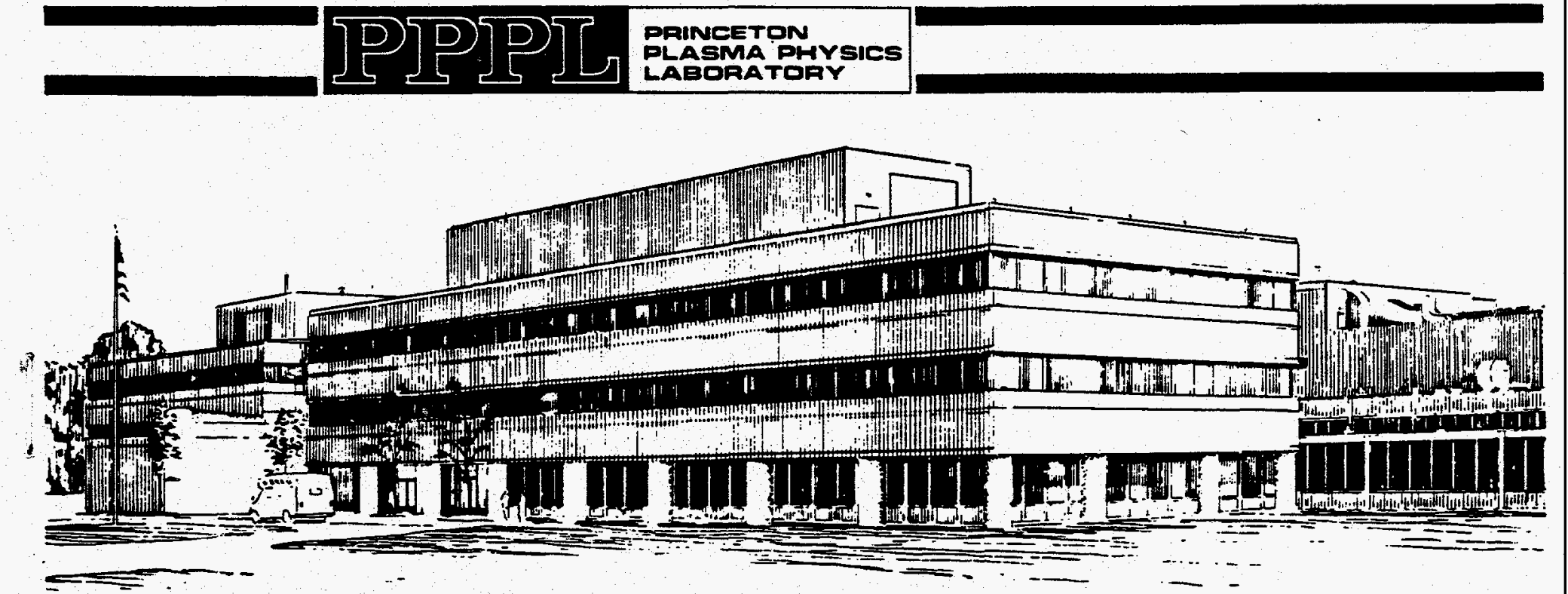

PRINCETON UNIVERSITY, PRINCETON, NEW JERSEY 


\title{
NOTICE
}

This report was prepared as an account of work sponsored by an agency of the United States Government. Neither the United States Government nor any agency thereof, nor any of their employees, makes any warranty, express or implied, or assumes any legal liability or responsibility for the accuracy, completeness, or usefulness of any information, apparatus, product, or process disclosed, or represents that its use would not infringe privately owned rights. Reference herein to any specific commercial produce, process, or service by trade name, trademark, manufacturer, or otherwise, does not necessarily constitute or imply its endorsement, recommendation, or favoring by the United States Government or any agency thereof. The views and opinions of authors expressed herein do not necessarily state or reflect those of the United States Government or any agency thereof.

\author{
NOTICE \\ This report has been reproduced from the best available copy. \\ Available in paper copy and microfiche. \\ Number of pages in this report: 23 \\ DOE and DOE contractors can obtain copies of this report from: \\ Office of Scientific and Technical Information \\ P.O. Box 62 \\ Oak Ridge, TN 37831 ; \\ (615) $576-8401$.
}

This report is publicly available from the:

National Technical Information Service

Department of Commerce

5285 Port Royal Road

Springfield, Virginia 22161

(703) $487-4650$ 


\section{DISCLAIMER}

Portions of this document may be illegible in electronic image products. Images are produced from the best available original document. 


\title{
Alfvénic Behavior of Alpha Particle Driven Ion Cyclotron Emission in TFTR
}

S. Cauffman and R. Majeski

Princeton Plasma Physics Laboratory, P.O. Box 451, Princeton, New Jersey 08543

K. G. McClements and R. O. Dendy

UKAEA Government Divison, Fusion, Culham, Abingdon, Oxfordshire, OX14 3DB UK (Euratom/UKAEA Fusion Association)

\begin{abstract}
Ion cyclotron emission (ICE) has been observed during D-T discharges in the Tokamak Fusion Test Reactor (TFTR), using rf probes located near the top and bottom of the vacuum vessel. Harmonics of the alpha cyclotron frequency $\left(\Omega_{\alpha}\right)$ evaluated at the outer midplane plasma edge are observed at the onset of the beam injection phase of TFTR supershots, and persist for approximately $100-250 \mathrm{~ms}$. These results are in contrast with observations of ICE in JET, in which harmonics of $\Omega_{\alpha}$ evolve with the alpha population in the plasma edge. Such differences are believed to be due to the fact that newly-born fusion alpha particles are super-Alfvénic near the edge of JET plasmas, while they are sub-Alfvénic near the edge of TFTR supershot plasmas. In TFTR discharges with edge densities such that newly-born alpha particles are super-Alfvénic, alpha cyclotron harmonics are observed to persist. These results are in qualitative agreement with numerical calculations of growth rates due to the magnetoacoustic cyclotron instability.
\end{abstract}




\section{INTRODUCTION}

Cyclotronic emission has been observed during deuterium-tritium operation in both JET ${ }^{1}$ and TFTR. ${ }^{2,3}$ In both cases, multiple harmonics of $\Omega_{\alpha}$ (the alpha cyclotron frequency evaluated near the outer midplane edge of the plasma) are observed. On JET, the evolution of these harmonics follows that of the edge alpha particle population, and shows clear correlations with MHD events. On TFTR, emission at harmonics of $\Omega_{\alpha}$ is also observed, but its temporal evolution is very different. In a typical TFTR supershot, $\boldsymbol{\Omega}_{\boldsymbol{\alpha}}$ harmonics are observed within $50 \mathrm{~ms}$ of beam injection, but then disappear within 100-250 ms. These modes are then replaced by a new, distinct set of harmonics of $\Omega_{\mathrm{D}}$ and $\Omega_{\mathrm{T}}$, the cyclotron frequencies of the injected species. Like the $\Omega_{\alpha}$ emission, these frequencies correspond to a locus of emission near the outer midplane plasma edge, but at a slightly smaller major radius. While the magnetic field inferred from $\Omega_{\alpha}$ (neglecting the Doppler shift) corresponds to a location slightly beyond the plasma edge (in the vacuum region), the field inferred from $\Omega_{D}$ and $\Omega_{T}$ corresponds to a location just inside the plasma edge. Typical early $\left(\Omega_{\alpha}\right)$ and late $\left(\Omega_{\mathrm{D}}\right.$ and $\left.\Omega_{\mathrm{T}}\right)$ spectra, as well as the locations of cyclotron resonances within the plasma, are presented in figure 1. For comparison, ICE observations during DD plasmas in TFTR are described elsewhere. $2,3,4$

Before discussing measurements of alpha particle driven ICE in TFTR in further detail, we present a brief description of the magnetoacoustic (or Alfvén) cyclotron instability (MCI), and its implications for expected emission in TFTR and in JET. 


\section{THE MAGNETOACOUSTIC CYCLOTRON INSTABILITY}

The MCI has been identified as the probable mechanism behind fusion product driven ICE in both JET and TFTR, 5,6,7 While ICE can be modelled with varying degrees of sophistication, much of the relevant physics is captured by simply solving the local dispersion relation for a uniform plasma with conditions comparable to those in the plasma edge. Such a treatment verifies that ICE can, under the right conditions, be excited by fusion products 5,6 or by beam ions. 8 We limit the present discussion to the issue of alpha particle driven ICE. At the onset of neutral beam injection, the alpha particle population in the plasma edge is initially dominated by barely trapped particles born near the core on very wide banana orbits. Figure 2 depicts such an orbit in TFTR, while figure 3 presents the pitch angle distribution of alpha particles at the TFTR plasma edge, as calculated by the ORBIT particlefollowing code, ${ }^{9}$ which integrates fusion source profiles (calculated by TRANSP10) over particle orbits. A simple but reasonable model for the distribution of birth alpha particles at the plasma edge is thus $f_{\alpha} \propto \exp \left\{-\left(v_{\|}-v_{d}\right)^{2} / v_{r_{\|}}^{2}-\left(v_{\perp}-u\right)^{2} / v_{r_{\perp}}{ }^{2}\right\}$, where $v_{d}^{2}+u^{2}=v_{\alpha 0}{ }^{2}\left(v_{\alpha o}\right.$ is the alpha particle birth velocity) and $u / v_{d}=\tan \left(\theta_{0}\right)\left(\theta_{0}\right.$ is a pitch angle lying close to the trapped/passing boundary). Local dispersion relations for such distributions can be solved numerically, and in certain limits, analytically.5,6 In particular, as was shown in references 5 and 6 , if one lets $f_{\alpha} \propto \exp \left\{-\left(v_{\|}-v_{d}\right)^{2} / v_{r}^{2}\right\} \delta\left(v_{\perp}-u\right)$, takes the electrostatic limit, ignores Landau damping (appropriate if $k_{\|} \ll k_{\perp}$ ), and assumes $n_{\alpha}$ « $n_{i}$, one recovers, to lowest order, the fast Alfvén wave dispersion relation:

$$
\omega^{2}=\frac{1}{2} c_{A}^{2}\left[k^{2}+k_{\|}^{2}+k^{2} k_{\|}^{2} \frac{c_{A}^{2}}{\Omega_{i}^{2}}+\sqrt{\left(k^{2}+k_{\|}^{2}+k^{2} k_{\|}^{2} \frac{c_{A}^{2}}{\Omega_{i}^{2}}\right)^{2}-4 k^{2} k_{\|}^{2}}\right]
$$


with the first order correction yielding the growth rate:

$$
\gamma=\frac{\omega_{p \alpha}^{2}}{\omega_{p i}^{2}} \frac{\Omega_{i}^{4}}{\left(\Omega_{i}+\left(\omega-\Omega_{i}\right) N_{\|}^{2}\right)\left(\Omega_{i}-\left(\omega+\Omega_{i}\right) N_{\|}^{2}\right)}\left[\frac{n \Omega_{\alpha}}{k_{\|} v_{r}} M_{n}-\frac{2 u^{2}}{v_{r}^{2}} \eta_{n} N_{n}\right] \frac{\sqrt{\pi}}{2 \omega} \mathrm{e}^{-\eta_{n}^{2}}
$$

where $M_{n}$ and $N_{n}$ are given by:

$$
\begin{gathered}
M_{n}=2 n \frac{\omega}{\Omega_{i}}\left[J_{n}^{\prime 2}+\frac{1}{z_{a}^{2}}\left(n^{2}-z_{a}^{2}\right) J_{n}^{2}\right]-2 \frac{\omega^{2}-\Omega_{i}^{2}}{\Omega_{i}^{2}} \frac{J_{n} J_{n}{ }_{n}}{z_{a}}\left[n^{2} N_{\perp}^{2}-\left(z_{a}^{2}-2 n^{2}\right) N_{\|}^{2}\right] \\
\quad+\frac{2 J_{n} J_{n}^{\prime}}{z_{a}}\left(z_{a}^{2}-2 n^{2}\right) \\
N_{n}=-2 n \frac{\omega}{\Omega_{i}} \frac{J_{n} J_{n}^{\prime}}{z_{a}}+\frac{\omega^{2}-\Omega_{i}^{2}}{\Omega_{i}^{2}}\left[N_{\|}^{2}\left(\frac{n^{2} J_{n}^{2}}{z_{a}^{2}}+J_{n}^{\prime 2}\right)+N_{\perp}^{2} \frac{n^{2} J_{n}^{2}}{z_{a}^{2}}\right]+\frac{n^{2} J_{n}^{2}}{z_{a}^{2}}+J_{n}^{\prime 2}
\end{gathered}
$$

and where $N_{\|}=k_{\|} c_{A} / \omega, N_{\perp}=k_{\perp} c_{A} / \omega, \eta_{n}=\left(\omega-k_{\|} v_{d}-n \Omega_{\alpha}\right) / k_{\|} v_{r}, J_{n}$ is the Bessel function of order $n$ with argument $z_{a}=k_{\perp} u / \Omega_{\alpha}$, and $n$ is the integer for which $n \Omega_{\alpha}$ lies closest to $\omega$. These equations can be expressed in terms of the following dimensionless parameters: the ratio of the alpha particle density to the background ion density $\left(\xi \equiv n_{\alpha} / n_{i}\right)$, the mean alpha particle pitch angle $\left(\theta_{\mathrm{o}}\right)$, the propagation angle $\left(\tan \left(\theta_{k}\right) \equiv k_{\perp} / k_{\|}\right)$, the ratio of the alpha birth velocity to the Alfvén speed $\left(\zeta \equiv v_{\alpha o} / v_{A}\right)$, and the narrowness of $f_{\alpha}\left(\sigma \equiv v_{r} / u\right)$. Numerical calculations indicate that while the growth rate is proportional to $\xi$, the value of $\sigma$ required for instability is strongly dependent on $\zeta$ (see figures 4 and 5). If the alpha particles are super-Alfvenic (e.g. $\zeta=1.5$ ), the second alpha particle harmonic, for example, can be destabilized for values of $\sigma$ below 0.14; if the alpha particles are sub-Alfvénic (e.g. $\zeta=0.5$ ), the same harmonic is stabilized for values of $\sigma$ above 0.06 .6 One would expect, therefore, that while the initial edge alpha particle population is narrow enough, ICE would be observed as $\xi$ increases, but that as the distribution widens, the ICE would eventually be stabilized. Furthermore, this stabilization would be more easily achieved for smaller values of $\zeta$. 


\section{IMPLICATIONS FOR JET AND TFTR}

Due to the flatness of JET density profiles, $3.5 \mathrm{MeV}$ alpha particles are super-Alfvénic even near the plasma edge.11 TFTR supershots, on the other hand, are characterized by highly peaked density profiles, such as the one in figure 6. So while alpha particles are born super-Alfvénic in the core, they are sub-Alfvénic near the plasma edge. $\mathrm{MCI}$ theory would thus suggest that alpha particle driven ICE harmonics would be more easily excited in JET than in TFTR (which, indeed, is the case). In addition, the excitation of the MCI in TFTR depends on two competing processes: the rapid growth of the alpha particle population once beam heating commences, and the gradual widening of the alpha particle distribution function due to collisions. When alpha particle production begins, the distribution function at the plasma edge is very narrow, because the alpha particles have not yet slowed down and because only those with a narrow range of pitch angles (i.e. those that are barely trapped) will follow orbits carrying them through the plasma edge. As the alpha particle population continues to grow, however, the distribution function widens, eventually reaching the point at which the instability can no longer be excited. A simple analytic model of the evolution of the alpha particle distribution function (see reference 6 for a detailed description)

predicts that for parameters appropriate for the edge plasma in TFTR supershots, alpha particle driven ICE should be observed during approximately the first $100 \mathrm{~ms}$ of beam injection, with the growth rate peaking near $40 \mathrm{~ms}$. This prediction is qualitatively consistent with experimental observations. 


\section{ICE IN TFTR L-MODES}

Recently, ICE data were obtained during several TFTR discharges with edge densities high enough to ensure that $3.5 \mathrm{MeV}$ alpha particles were superAlfvénic even near the plasma edge. $\mathrm{MCI}$ theory suggests that alpha particle driven ICE should be more easily excited under such conditions, and, in fact, this turns out to be the case. We present in figures 7,8 , and 9 a comparison of data from three different discharges. The first is a typical supershot, in which edge alpha particles are sub-Alfvénic throughout the discharge. In this case, alpha particle driven ICE is observed only at the onset of beams. The second is a supershot in which an L-mode transition is induced by means of a large He puff. In this case, alpha particle driven ICE is observed briefly at the onset of beams, but also reappears after the puff, when the density is high enough that $\zeta>1$. The final case is an L-mode discharge for which the alpha particle birth speed is greater than the edge Alfvén speed throughout the beam phase. In this case, alpha particle driven ICE is observed immediately after the onset of beams, but persists until the beams are turned off. In all three cases, alpha particle driven ICE is observed only when the edge alpha particles have a very narrow distribution function, or when they are super-Alfvénic.

\section{DISCUSSION}

The data presented above provide valuable support for the MCI theory of ion cyclotron emission. While the local treatment described above is simplistic by construction, it nevertheless is qualitatively consistent with empirical observation. More elaborate models (such as the global eigenmode calculation presented in reference 7) should lead to further improvements in

our understanding. At present, several aspects of ICE in TFTR remain poorly understood. First, spatial localization to one region of the plasma seems 
insufficient, by itself, to account for the extreme narrowness of the observed modes. The alpha particle distribution function is described by a narrow drifting ring over a larger range of radii than the spectral line widths would indicate. We should also note, however, that a small fraction of alpha particle orbits extend beyond the outer midplane plasma edge. It may be that the least damped eigenmode is that with the lowest frequency accessible to the energetic species. (Recall that the locus of emission, neglecting any Doppler shift, is consistent with magnetic fields in the vacuum region beyond the plasma edge.) Second, the way in which the amplitude of alpha particle driven ICE in TFTR depends on global plasma parameters (e.g. fusion rate, beam power, plasma current) remains poorly understood. The ICE signal in JET, for example, has been demonstrated to be linearly proportional to the fusion rate over six orders of magnitude. ${ }^{1}$ On TFTR, while a comparison of the peak $\Omega_{\alpha}$ power with the peak D-T neutron rate also yields a regression coefficient close to unity, a large amount of scatter is also apparent. ${ }^{3}$ Given that the excitation of ICE is much more sensitive to the shape of the alpha particle distribution function in TFTR than it is in JET, its dependence on plasma conditions might be more complex as well. Finally, alpha particle driven ICE in TFTR exhibits an extremely rapid turn off at the end of the beam phase during the L-mode discharge (figure 6) presented earlier. Additional measurements of ICE during L-mode plasmas are planned.

\section{SUMMARY}

Emission at multiples of $\Omega_{\alpha}$ is observed during D-T discharges in TFTR. While this emission is highly transient when $v_{\alpha \circ}<v_{A}$, it reappears (or persists) when $v_{\alpha_{0}}>v_{A}$. These observations provide evidence for the 
Alfvénic nature of ICE, and are consistent with predictions based on local growth rate calculations for the Magnetoacoustic Cyclotron Instability.

\section{ACKNOWLEDGEMENTS}

This work was supported by US DoE contract number DE-AC02-76-CH03073, the United Kingdom Department of Trade and Industry, and Euratom. 


\section{REFERENCES}

[1] COTTRELL, G.A., et al., Nucl. Fusion 33 (1993) 1365.

[2] CAUFFMAN, S., MAJESKI, R., Rev. Sci. Instrum. 66 (1995) 817.

[3] CAUFFMAN, S., MAJESKI, R., Bull. Am. Phys. Soc. 39 (1994) 1675.

[4] GREENE, G., et al., Proceedings of the Seventeenth EPS, Amsterdam, 14B-IV (1990) 1540.

[5] DENDY, R.O., et al., Phys. Plasmas 1 (1994) 1918.

[6] MCCLEMENTS, K.G., et al., An interpretation of ion cyclotron emission from sub-Alfvénic fusion products in the Tokamak Fusion Test Reactor, submitted to Phys. Plasmas.

[7] GORELENKOV, N., CHENG, C.Z., to be published in Phys. Plasmas (June 1995).

[8] DENDY, R.O., et al., Phys. Plasmas 1 (1994) 3407.

[9] FELT, J., et al., Rev. Sci. Instrum. 61 (1990) 3262.

[10] BUDNY, R., et al., Nucl. Fusion 34 (1994) 1247.

[11] REBUT, P., et al., Nucl. Fusion 32 (1992) 187. 


\section{FIGURE CAPTIONS}

FIG. 1. Early and late ICE spectra from a DT supershot. The apparent locus of emission (a) and the spectral structure at $66 \mathrm{~ms}$ (b) is distinct from that at $243 \mathrm{~ms}(\mathrm{c})$ after the onset of neutral beam injection.

FIG. 2. Barely trapped alpha orbit passing through the plasma edge. Orbits near the plasma edge will sample a significant fraction of the plasma core if they are barely trapped.

FIG. 3. Alpha pitch angle distribution at the plasma edge. Because most alpha particles are born near the core, their population near the edge will be dominated by those that are barely trapped.

FIG. 4. MCI growth rates for super-Alfvenic alpha particles. Shown here are growth rates for $n=2, \xi=10^{-4}, \theta_{k}=80^{\circ}, \theta_{0}=135^{\circ}, \zeta=1.5$, and three values of $\sigma: 0.12,0.13$, and 0.14 .

FIG. 5. MCI growth rates for sub-Alfvenic alpha particles. Shown here are growth rates for the same parameters as in figure 4 , except $\zeta=0.5$, and $\sigma=0.050,0.055$, and 0.060 .

FIG. 6. Supershot density profile. The electron density, as well as the critical value above which $3.5 \mathrm{MeV}$ alpha particles will be super-Alfvénic, is plotted as a function of major radius. Near the edge, alpha particles are subAlfvénic.

FIG. 7. Alpha particle driven ICE during a typical supershot. The neutron source rate (a), edge electron density (b), and ICE power in the $\Omega_{\alpha}$ fundamental (c) are plotted as functions of time. Birth alpha particles are subAlfvénic in the plasma edge, and the $\Omega_{\alpha}$ fundamental is only excited briefly at the onset of neutral beam injection. 
FIG. 8. Alpha particle driven ICE during a supershot-to-L-mode transition. The same quantities are shown as in figure 7 . The $\Omega_{\alpha}$ fundamental is excited briefly at the onset of neutral beam injection, but reappears after a He puff raises the edge density so that $v_{\alpha 0}>v_{A}$.

FIG. 9. Alpha particle driven ICE during an L-mode shot. The same quantities are shown as in figures 7 and 8 . In this case, $v_{\alpha_{0}}>v_{A}$ throughout the beam injection phase. The $\Omega_{\alpha}$ fundamental is excited at the onset of neutral beam injection, and persists untii the beams are turned off. 


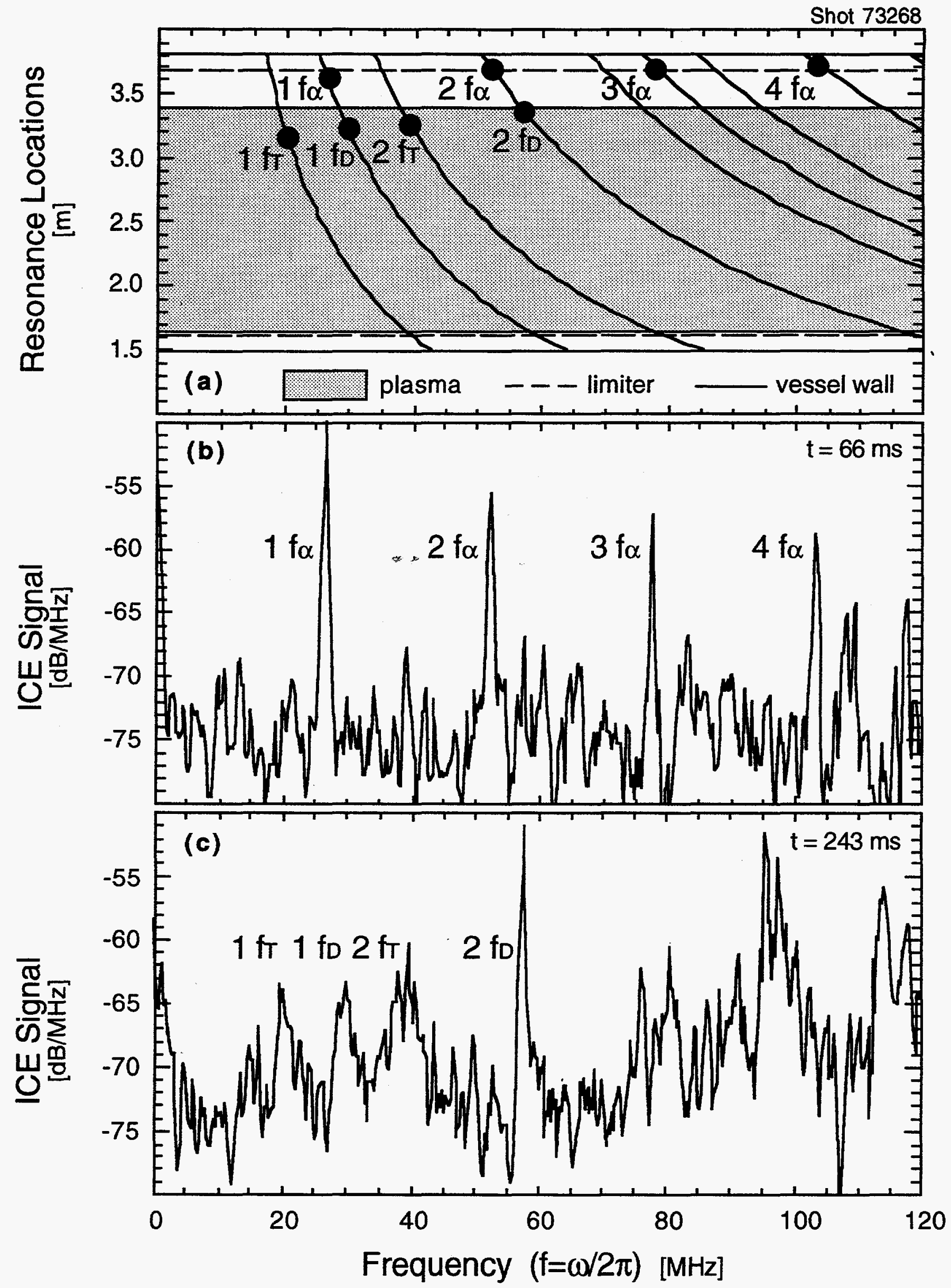




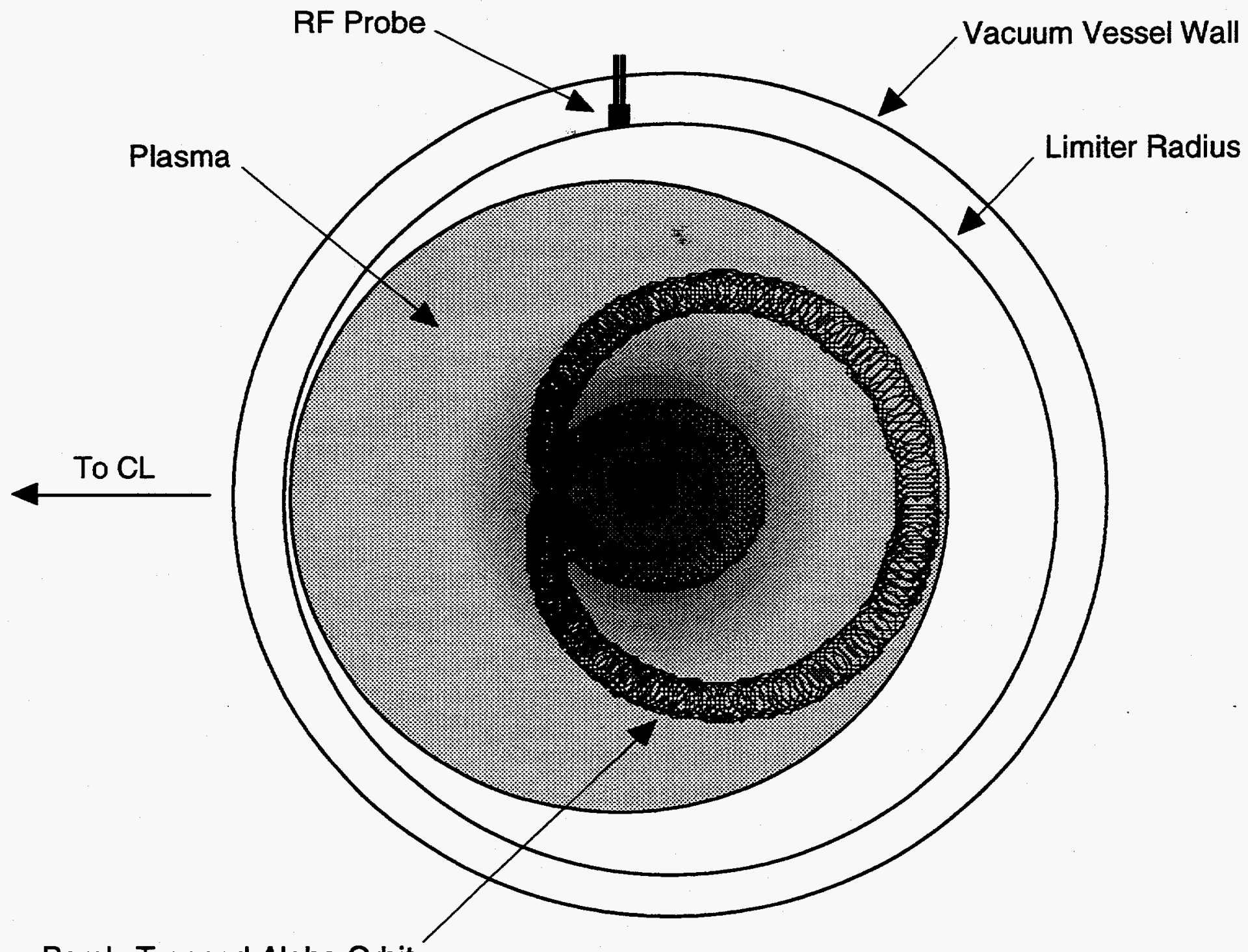

Barely Trapped Alpha Orbit 


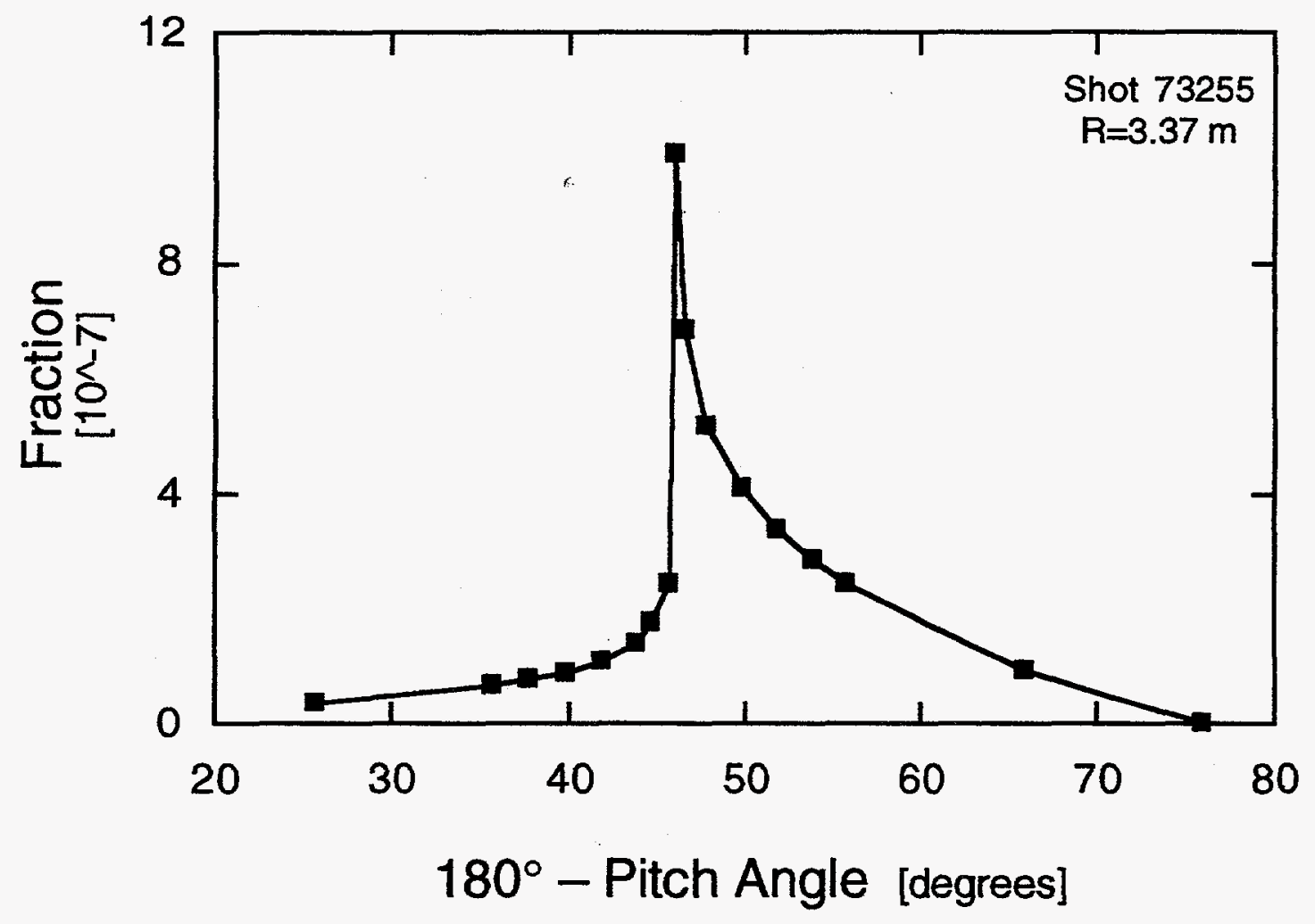

Fig. 3 


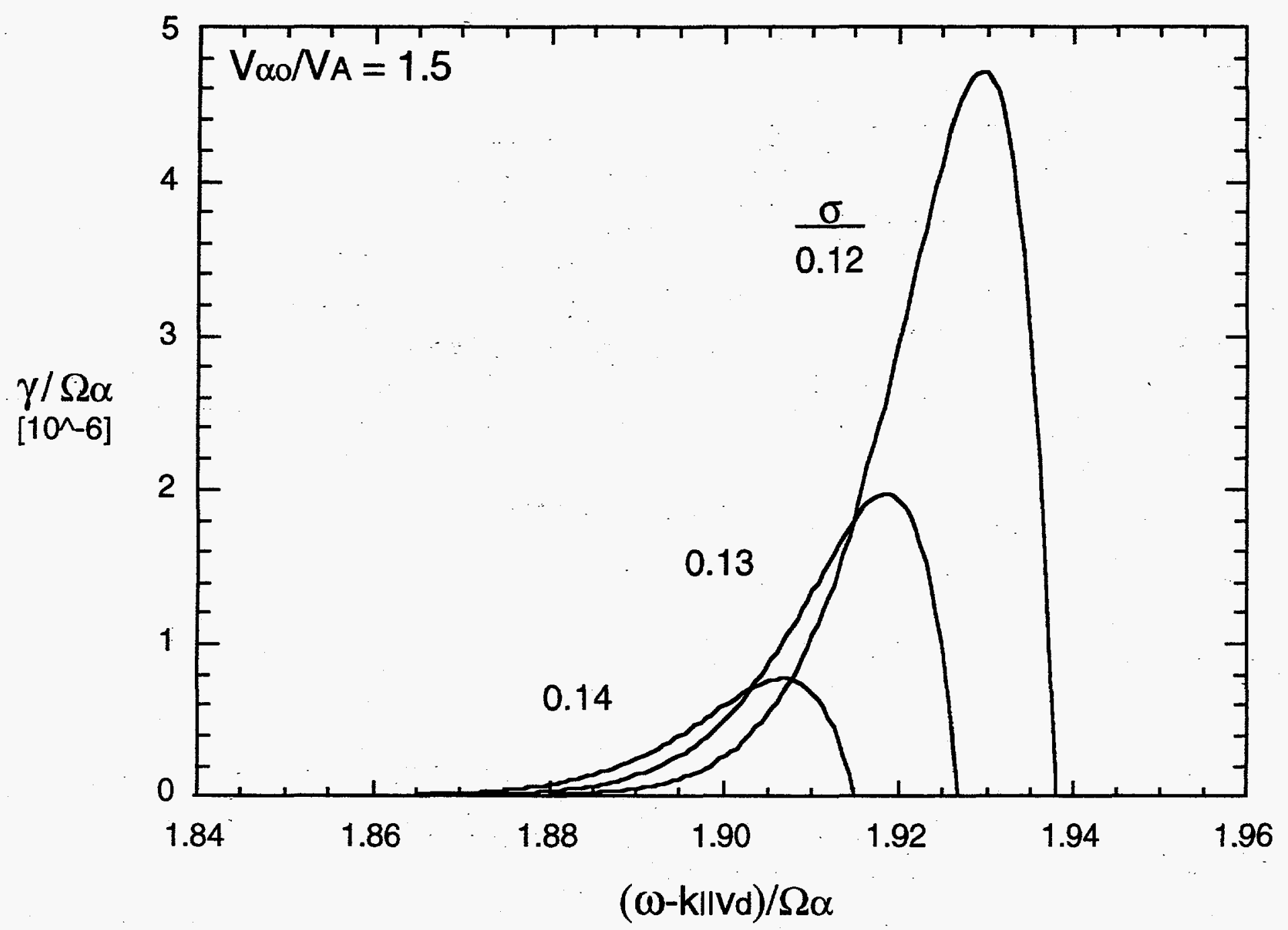

Fig. 4 


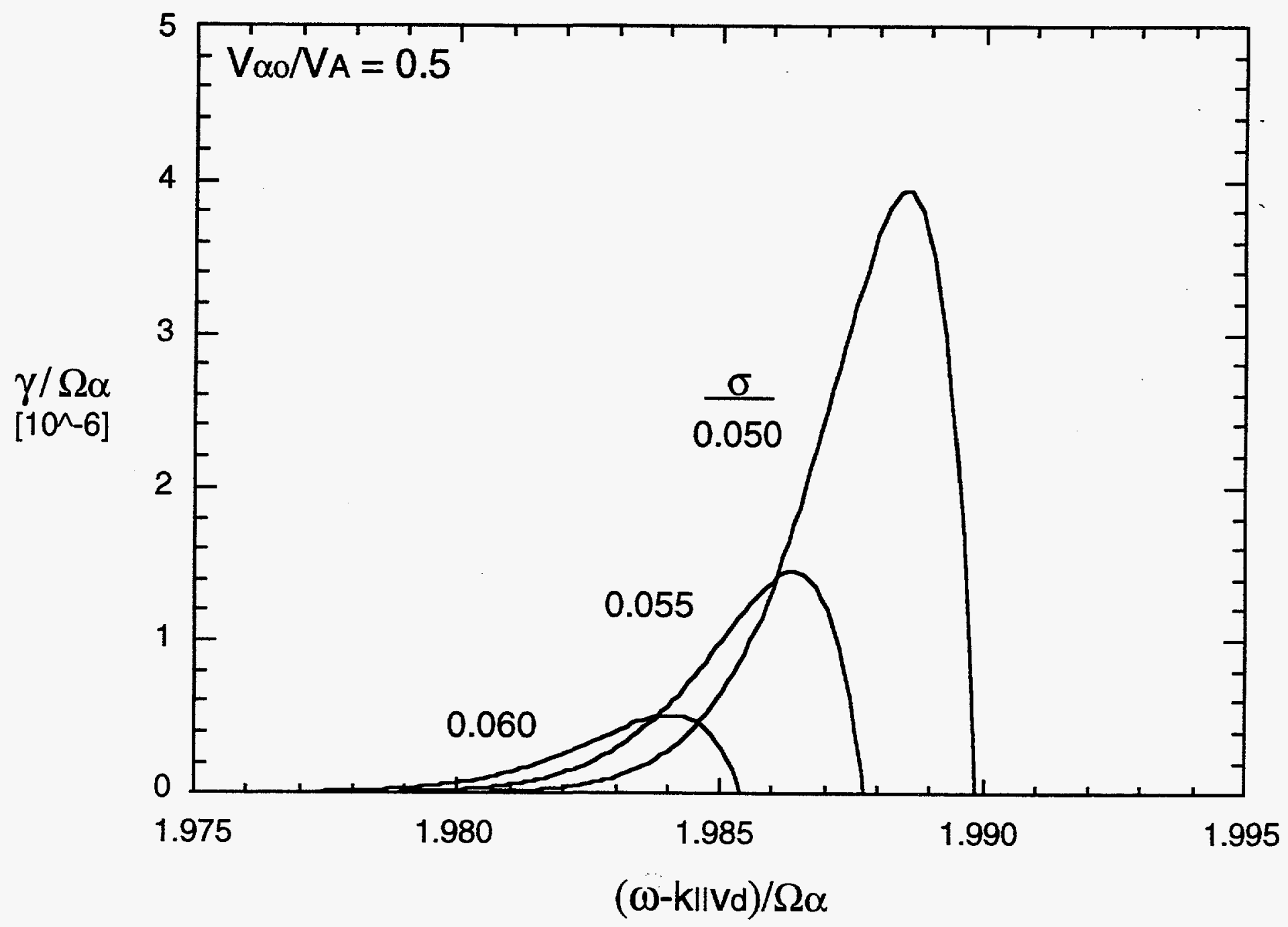

Fig. 5 


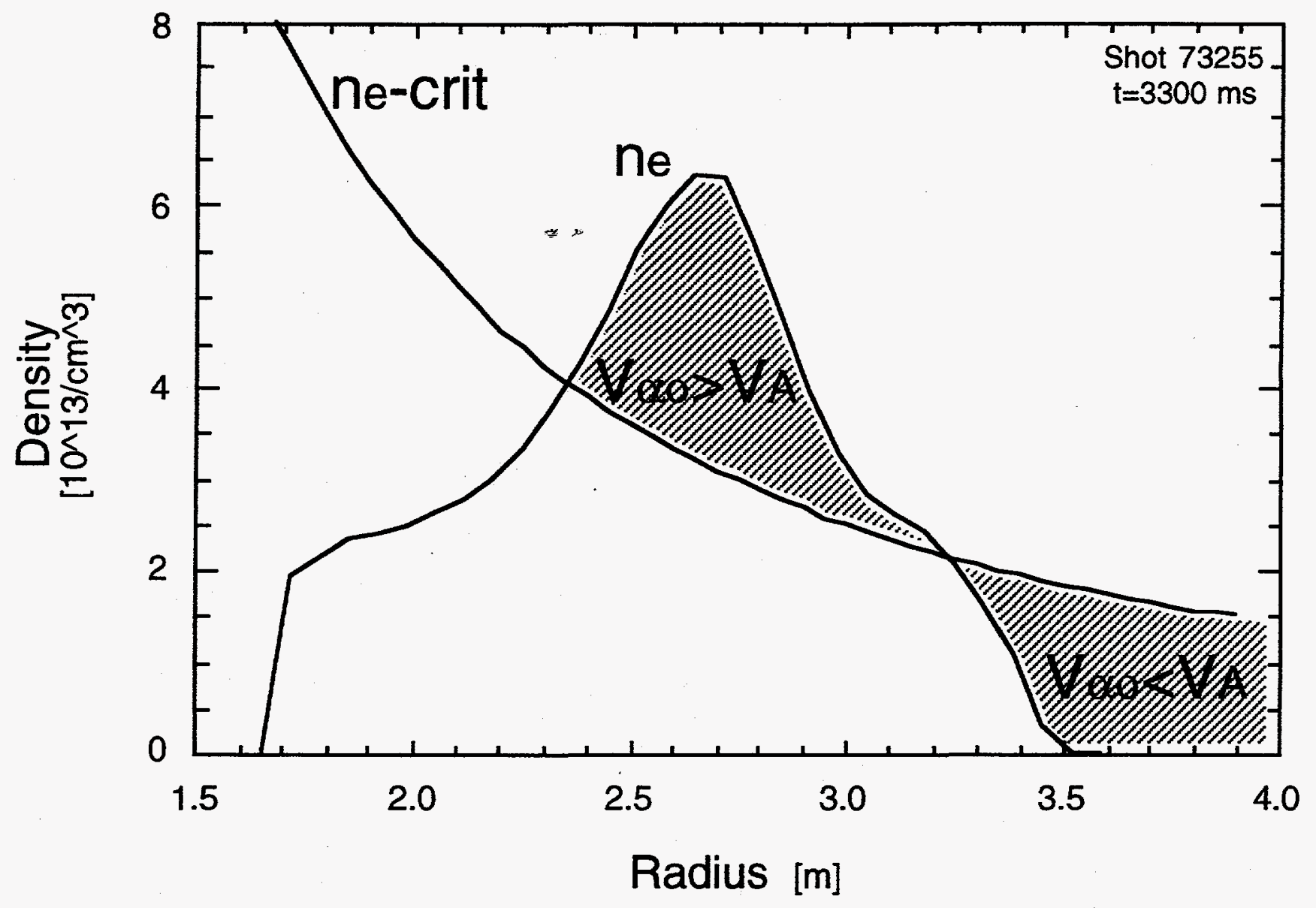

Fig. 6 


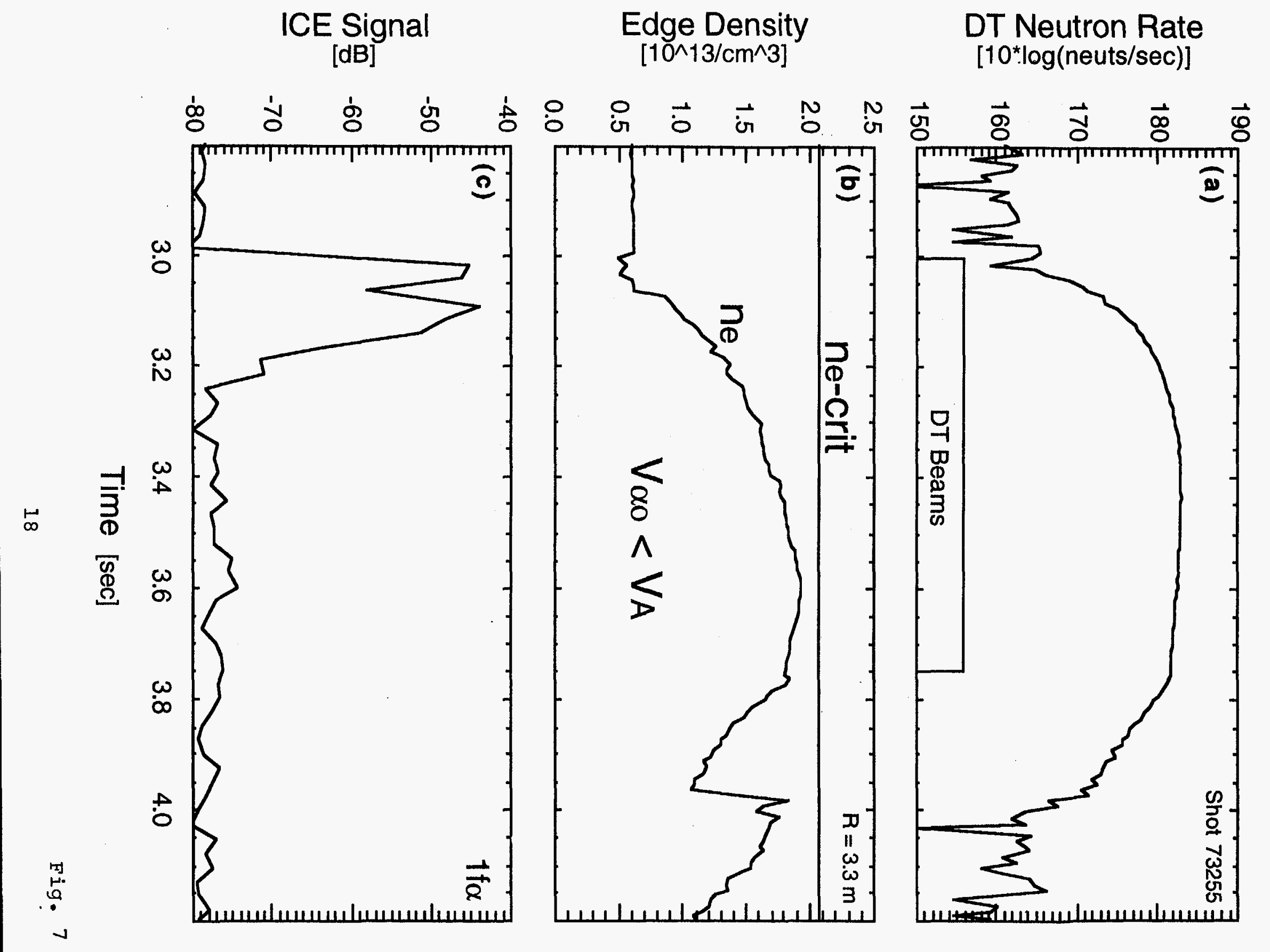




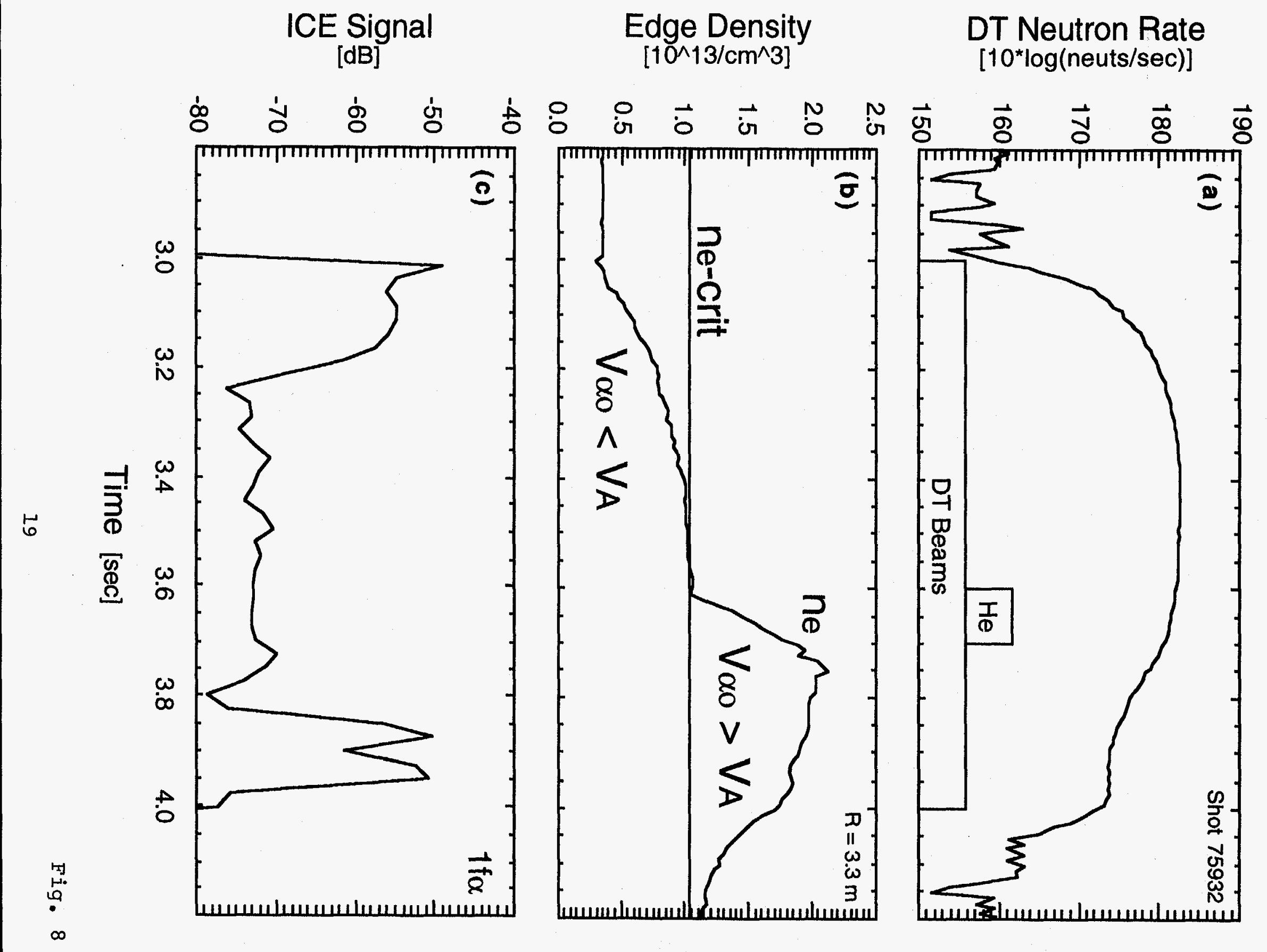



Dr. F. Paoloni, Univ. of Wollongong, AUSTRALIA

Prof. R.C. Cross, Univ. of Sydney, AUSTRALIA

Plasma Research Lab., Australian Nat. Univ., AUSTRALIA

Prof. I.R. Jones, Flinders Univ, AUSTRALIA

Prof. F. Cap, Inst for Theoretical Physics, AUSTRIA

Prof. M. Heindler, Institut tûr Theoretische Physik, AUSTRIA

Prof. M. Goossens, Astronomisch instituut, BELGIUM

Ecole Royale Militaire, Lab. de Phy. Plasmas, BELGIUM

Commission-European, DG. XII-Fusion Prog., BELGIUM

Prof. R. Bouciqué, Rijksuniversiteit Gent, BELGIUM

Dr. P.H. Sakanaka, Instituto Fisica, BRAZIL

Prof. Dr. I.C. Nascimento, Instituto Fisica, Sao Paulo, BRAZIL Instituto Nacional De Pesquisas Espaciais-INPE, BRAZIL

Documents Office, Atomic Energy of Canada Ltd., CANADA

Ms. M. Morin, CCFMTokamak de Varennes, CANADA

Dr. M.P. Bachynski, MPB Technologies, Inc., CANADA

Dr. H.M. Skarsgard, Univ. of Saskatchewan, CANADA

Prof. J. Teichmann, Univ. of Montreal, CANADA

Prof. S.R. Sreenivasan, Univ, of Calgary, CANADA

Prof. R. Marchand, INRS-Energie et Materiaux, CANADA

Dr. R. Bolton, Centre canadien de fusion magnétique, CANADA

Dr. C.R. James, Univ. of Alberta, CANADA

Dr. P. Lukác, Komenského Universzita, CZECHOSLOVAKIA

The Librarian, Culham Laboratory, ENGLAND

Library, R61. Rutherford Appleton Laboratory, ENGLAND

Mrs. S.A. Hutchinson, JET Library, ENGLAND

Dr. S.C. Shama, Univ. of South Pacific, FIJI ISLANDS

P. Mähönen, Univ. of Helsinki, FINLAND

Prof. M.N. Bussac, Ecole Polytechnique,, FRANCE

C. Mouttet, Lab. de Physique des Milieux lonisés, FRANCE

J. Radet, CEN/CADARACHE - Bat 506, FRANCE

Prof. E. Economou, Univ. of Crete, GREECE

Ms. C. Ainni, Univ. of loannina, GREECE

Preprint Library, Hungarian Academy of Sai., HUNGARY

Dr. B. DasGupta, Saha Inst. of Nuclear Physics, INDIA

Dr. P. Kaw, Inst. for Plasma Research, INDIA

Dr. P. Rosenau, Israel Inst of Technology, ISRAEL

Librarian, intemational Center for Theo Physics, ITALY

Miss C. De Palo, Associazione EURATOM-ENEA, ITALY

Dr. G. Grosso, Istituto di Fisica del Plasma, ITALY

Prof. G. Rostangni, Istituto Gas lonizzati Del Cnr, ITALY
Dr. H. Yamato, Toshiba Res \& Devel Center, JAPAN

Prof. I. Kawakami, Hiroshima Univ., JAPAN

Prof. K. Nishikawa, Hiroshima Univ., JAPAN

Librarian, Naka Fusion Research Establishment, JAERI, JAPAN

Director, Japan Atomic Energy Research Inst., JAPAN

Prof. S. Itoh, Kyushu Univ., JAPAN

Research Info. Cr., National Instit. for Fusion Scienć, JAPAN

Prof. S. Tanaka, Kyoto Univ., JAPAN

Library, Kyoto Univ., JAPAN

Prot. N. Inoue, Univ. of Tokyo, JAPAN

Secretary, Plasma Section, Electrotechnical Lab., JAPAN

Dr. O. Mitarai, Kumamoto Inst. of Technology, JAPAN

Dr. G.S. Lee, Korea Basic Sci. Ctr., KOREA

J. Hyeon-Sook, Korea Atomic Energy Research Inst., KOREA

D.I. Choi, The Korea Adv. Inst. of Sci. \& Tech., KOREA

Leandro Melendez Lugo, Inst. Nac1. de Inves. Nud, MEXICO

Prof. B.S. Liley, Univ. of Waikato, NEW ZEALAND

Inst of Physics, Chinese Acad Sci PEOPLE'S REP. OF CHINA

Library, Inst. of Plasma Physics, PEOPLE'S REP. OF CHINA

Tsinghua Univ. Library, PEOPLE'S REPUBLIC OF CHINA

Z. Li, S.W. Inst Physics, PEOPLE'S REPUBLIC OF CHINA

Prof. J.A.C. Cabral, Instituto Superior Tecnico, PORTUGAL

Prof. M.A. Hellberg, Univ. of Natal, S. AFRICA

Prof. D.E. Kim, Pohang Inst. of Sci. \& Tech., SO. KOREA

Prof. C.I.E.M.A.T, Fusion Division Library, SPAIN

Dr. L. Stentio, Univ. of UMEA, SWEDEN

Library, Royal Inst. of Technology, SWEDEN

Prof. H. Witheimson, Chalmers Univ. of Tech., SWEDEN

Centre Phys. Des Plasmas, Ecole Polytech, SWITZERLAND

Bibliotheek, Inst. Voor Plasma-Fysica, THE NETHERLANDS

Asst. Prot. Dr. S. Cakir, Middle East Tech. Univ., TURKEY

Dr. V.A. Glukhikh,Sci. Res. Inst. Electrophys.I Apparatus, USSR

Dr. D.D. Ryutov, Siberian Branch of Academy of Sci., USSR

Dr. G.A. Eliseev, I.V. Kurchatov Inst., USSR

Librarian, The Ukr.SSR Academy of Sciences, USSR

Or. L.M. Kovrizhnykh, Inst. of General Physics, USSA

Kernforschungsanlage GmbH, Zentralbibliothek, W. GERMANY Bibliothek, Inst. Für Plasmaforschung, W. GERMANY

Prof. K. Schindier, Ruhr-Universitát Bochum, W. GERMANY

Dr. F. Wagner, (ASDEX), Max-Planck-Institut, W. GERMANY

Librarian, Max-Planck-Institut, W. GERMANY 